Article

\title{
Study on the Fault Diagnosis Method of Scraper Conveyor Gear under Time-Varying Load Condition
}

\author{
Shuanfeng Zhao* $*$, Pengfei Wang and Shijun Li \\ School of Mechanical Engineering, Xi'an University of Science and Technology, Xi'an 710054, China; \\ pengfeiwang08@163.com (P.W.); ajun386@163.com (S.L.) \\ * Correspondence: zsf@xust.edu.cn; Tel.: +86-029-8558-3159
}

Received: 16 June 2020; Accepted: 20 July 2020; Published: 23 July 2020

check for updates

Featured Application: The method proposed in our paper can be used in the field of gear fault diagnosis of low-speed and heavy-duty machines. This method uses the stator current signal of the motor for fault diagnosis, and preprocesses the original current to filter the interference of fundamental frequency and the load impact, so as to enhance the gear failure characteristic frequency. The gear failure characteristic frequency can be easily extracted from the preprocessed current. This diagnostic method does not require the installation of sensors and is not affected by environmental factors.

\begin{abstract}
Vibration signal is often used in traditional gear fault diagnosis techniques. However, the working face of the scraper conveyor is narrow, harsh and easily explosive, so it is inconvenient to obtain vibration signals by installing sensors. Motor current signature analysis (MCSA) is a fault-diagnosis method without sensor installation, which is easier to realize in the mine. Therefore, a fault diagnosis method for local gear fault, which is based on bispectral analysis (BA) of analytical signal envelope obtained by processing a stator current under time-varying load condition, is proposed in our paper. In this method, the fault frequency component is enhanced by eliminating the interference of fundamental frequency and coal flow impact. Then, the enhanced fault frequency component is extracted by BA, and a quantitative analysis of the fault strength under time-varying load is carried out from the perspective of energy. Finally, the proposed method is verified on the number HB-kpl-75 scraper conveyor reducer, and the results show that this method can successfully diagnose the failure of the scraper conveyor gear under time-varying load conditions.
\end{abstract}

Keywords: scraper conveyor; gear fault diagnosis; motor current signature analysis; bispectral analysis

\section{Introduction}

The cooperative work of the scraper conveyor with the shearer and the hydraulic support is the necessary condition to make the fully mechanized mining face work efficiently. A scraper conveyer is a typical low-speed and heavy-duty machine, which is mainly used to transport the coal cut by the shearer from the coal wall. The load of the scraper conveyor is mainly affected by the speed of the shearer cutting the coal wall. However, the amount of coal mined by the shearer per unit time is not stable, so the coal flow transported by a scraper conveyor will fluctuate. In addition, the load of the scraper conveyor is also affected by the horizontal and vertical inclination of the working face, so the load of the scraper conveyor has obvious time-varying characteristics. Under the condition of a time-varying load, the transmission gear will produce frequent torsional vibration fluctuation [1,2], which makes the reducer gear of the scraper conveyor prone to local faults. The gear failure is one of 
the main reasons that cause the scraper conveyor to stop. Therefore, it is necessary to diagnose the gear fault under time-varying load conditions.

The traditional fault diagnosis method mainly uses the vibration signal of mechanical devices [3-6]. This diagnosis method is sensitive to the change of the sensors' installation position and the external environment. Besides, the sensors are voluminous and expensive [7-9]. However, the fully mechanized mining face is narrow, harsh and dusty, so it is hard to install and work the vibration signal sensor. Thus, it is not easy to accomplish the fault of the scraper conveyor gear by vibration signal. Nevertheless, motor current signature analysis (MCSA) is a non-intrusive and sensor-free fault diagnosis method [10]. Compared with traditional vibration signal analysis, it has the advantages of easy signal acquisition, small space occupation and no environmental interference [11,12]. Therefore, MCSA is more suitable for the fault diagnosis of the scraper conveyor reducer gears in the fully mechanized coal face. Figure 1 is the fully mechanized coal face in the mine.

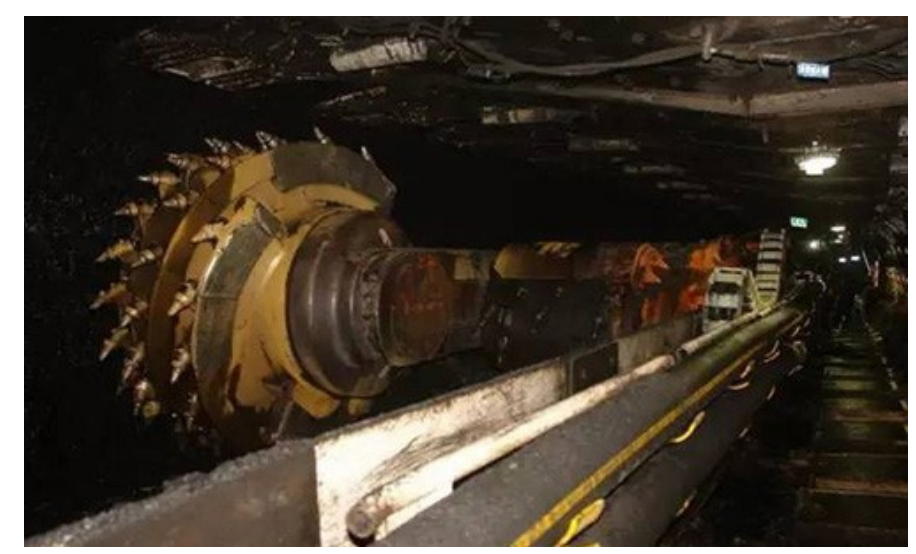

Figure 1. The fully mechanized coal face in the mine.

Initially, the MCSA was used to diagnose the fault of the motor body $[13,14]$, and it was gradually applied to the fault diagnosis of rotating machinery $[10,15,16]$. Literature $[17-20]$ shows that when gear failure occurs, the failure position can cause the periodic impact of load torque. These shocks caused by gear failure will modulate the stator current of the motor [21], which makes a series of frequency sidebands around the fundamental frequency appear in the current signal spectrum [22]. However, the scraper conveyor adopts the variable frequency conversion input current, so there is a strong basic frequency interference component in its working current. Meanwhile, when the scraper conveyor is working, the amount of coal falling may sudden increase or the scraper chain may get stuck. The impact characteristics and basic frequency interference caused by these conditions will weaken the fault characteristics in the current, which makes it difficult to extract gear fault information from the original current. Therefore, it is necessary to preprocess the original current, so as to enhance the fault frequency component.

The current signal preprocessing includes two parts: extracting the fault frequency band and eliminating the fundamental frequency interference. Aiming at the interference of coal flow impact and scraper chain impact in the current signal, the original current signal is decomposed into fault frequency band signal and impact frequency band signal by wavelet packet multi-scale decomposition (WPMD) in our method. Compared with the results of various decomposition scales, the optimal decomposition scale is found to extract the frequency band signal of gear fault to eliminate the interference of coal flow load and scraper chain impact to the greatest extent. Aiming at the strong fundamental frequency interference in the current, the method of amplitude demodulation is used to eliminate those interferences. The demodulation signal can effectively retain the fault components in the current signal, and the Hilbert transform (HT) is a small amount of calculation amplitude demodulation method. Therefore, the envelope of the current demodulation signal obtained by HT can effectively eliminate 
the current fundamental frequency interference. After the preprocessing operation, the frequency component of gear fault can obviously be enhanced. The current fundamental frequency component and gear fault frequency component will make the current of the scraper conveyor have obvious nonlinear characteristics. In addition, the scraper conveyor bears a relatively large time-varying load in the process of operation, so the operation state of each transmission part changes all the time. The instability of the transmission parts will cause the Gauss noise in the scraper conveyor current. Considering the characteristics of bispectral (BA), such as phase information retention, Gaussian noise elimination and good nonlinear current signal recognition [23,24], the fault frequency component under time-varying load conditions can be effectively extracted by BA. Under different load conditions, the fault information intensity from the current of scraper conveyor is also different. The intensity of the gear fault component in the current can cause the change of energy distribution in different frequency bands of the current. Therefore, from the energy point of view, the gear fault information in the current can be quantitatively analyzed under time-varying load conditions. Overall, a method for the local fault diagnosis of the gear based on the BA of an analytical signal envelope of stator current is proposed.

The remainder of our paper is outlined as follows. Section 2.1 establishes the mathematical model of the fault current. Section 2.2 proposes a current preprocessing method based on WPMD and HT. Section 2.3 proposes a fault feature frequency extraction method based on the BA of signal envelope in the fault frequency band and a fault quantitative analysis method based on bispectrum entropy (BE). Section 3 is the experimental part of our paper. Section 4 is the experimental results and discussion. Section 5 summarizes the work of our paper.

\section{Fault Diagnosis Method of Scraper Conveyor Gear}

Figure 2 is the workflow of our paper, which mainly includes four parts: data acquisition, current signal preprocessing, fault feature frequency extraction and fault quantitative analysis. The current signal preprocessing includes two sub modules: extracting the fault frequency band and suppressing the fundamental frequency interference.

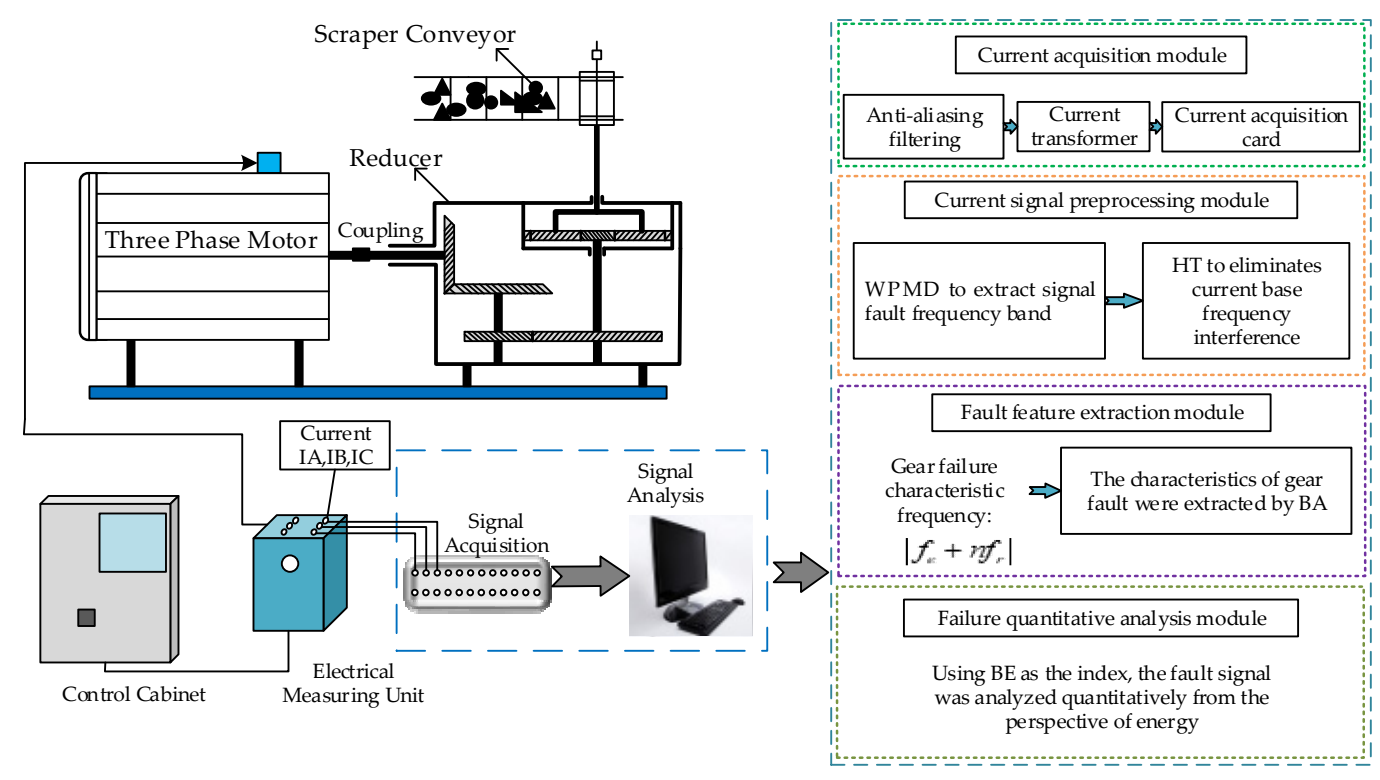

Figure 2. Workflow of the fault diagnosis. The meanings of the symbols and abbreviations in the figure are as follows: $\mathrm{I}_{\mathrm{A}}, \mathrm{I}_{\mathrm{B}}, \mathrm{I}_{\mathrm{C}}$ represents the three-phase current; WPMD—wavelet packet multi-scale decomposition; HT-Hilbert transform; BA-bispectral analysis.

The function of current acquisition module in Figure 2 is to collect the stator current signal of the scraper conveyor motor. The purpose of anti-aliasing filtering is to eliminate frequency aliasing. After 
the current acquisition was completed, the current was preprocessed. Then, the fault characteristic frequency of the preprocessed current was extracted and the fault was analyzed. The fault diagnosis method mentioned in our article is shown in Figure 3.

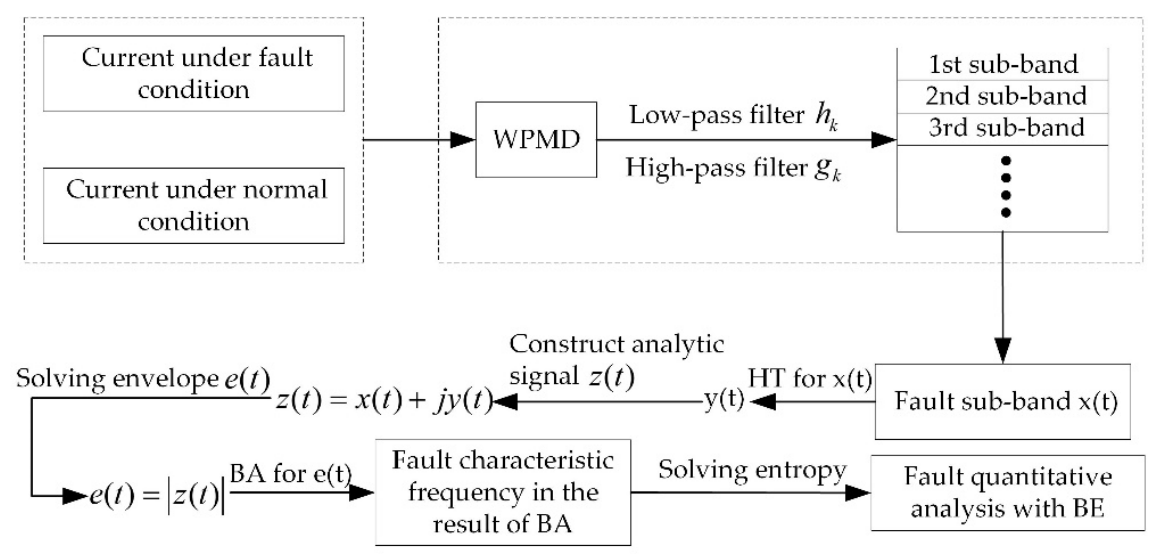

Figure 3. The fault diagnosis method. BE: bispectrum entropy.

WPMD was used to decompose the currents under normal and faulty conditions into a series of sub-bands, so as to realize the extraction of the fault band signal, and filter out the sub-bands including the impact interference of the coal flow load and scraper chain. Then, the extracted fault band signal $x(t)$ was demodulated by HT to obtain the demodulated signal $y(t)$. Combining $x(t)$ and $y(t)$ constructed the analytical signal $z(t)$ and solved the envelope $|z(t)|$. The purpose of solving the envelope was to suppress the fundamental frequency interference. Finally, BA was used to extract the characteristic frequency of the gear fault, and the strength of the fault signal in current was quantitatively analyzed by $\mathrm{BE}$.

\subsection{Mathematical Model of Fault Current}

The scraper conveyor used a three-phase motor as the power source. The output speed of the motor was decelerated by the reducer and then the power was transmitted to the sprocket, which drove the scraper chain to transport the coal flow. The scraper conveyor transport system and motor model are shown in Figure 4. When the gear failure occurred in the reducer, the electromagnetic torque and current would be affected by the gear failure. Finally, the current will contain the gear failure feature information. The influence mechanism of gear failure on current will be analyzed below.

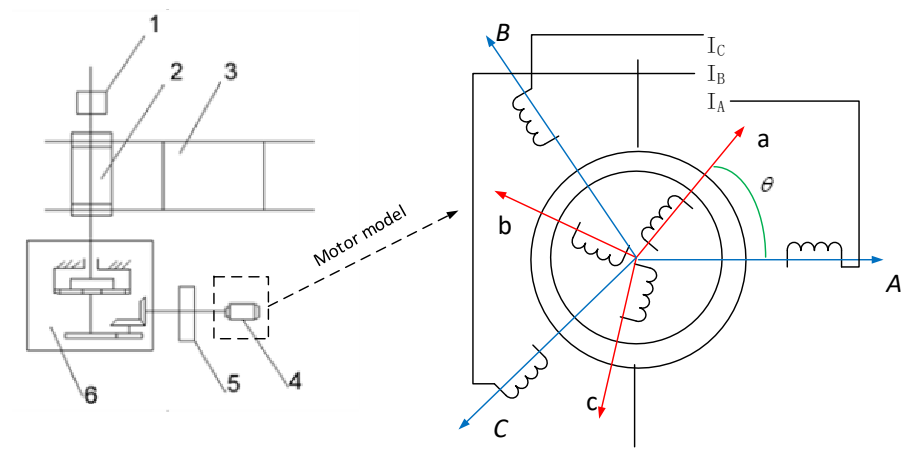

Figure 4. Scraper conveyor transport system and motor model. The meanings of the symbols and serial numbers in the figure are as follows: 1-sprocket; 2-blind axis; 3-scraper chain; 4-motor; 5-hydraulic coupling; and 6-reducer; A, B, C-axis of stator winding; a, b, c-axis of rotor winding; $\mathrm{I}_{\mathrm{A}}, \mathrm{I}_{\mathrm{B}}, \mathrm{I}_{\mathrm{C}}$ - three-phase current; $\theta$-space angular displacement. 
The electromagnetic torque equation of the scraper conveyor motor can be expressed as

$$
T_{e}=J \frac{d \omega_{m}}{d t}+T_{L}+B \omega_{m}
$$

where $T_{e}$ represents the electromagnetic torque of the motor, $T_{L}$ is the friction torque of the transmission system, $B$ is the load torque of the scraper conveyor, $J$ is the inertia of the system, and $\omega_{m}$ represents the angular speed of the motor. When the gear failure occurs in the reducer, the motor speed and electromagnetic torque will fluctuate $[25,26]$. In this case, the electromagnetic torque, load torque and rotational speed can be decomposed into a constant and cosine component, respectively, expressed as

$$
\left\{\begin{array}{l}
T_{e}=T_{e 0}+\sum_{i} T_{e i} \cos \left(2 \pi f_{i} t+\varphi_{e i}\right) \\
T_{L}=T_{L 0}+\sum_{i} T_{L i} \cos \left(2 \pi f_{i} t+\varphi_{L i}\right) \\
\omega_{m}=\omega_{m 0}+\sum_{i} \omega_{m i} \cos \left(2 \pi f_{i} t+\varphi_{m i}\right)
\end{array}\right.
$$

where $T_{e 0}, T_{L 0}$ and $\omega_{m 0}$ represent the mean values of the electromagnetic torque, load torque and rotational speed, respectively; $f_{i}$ represents the frequency of the electromagnetic torque, load torque and rotational speed; $\varphi_{e i}, \varphi_{L i}$ and $\varphi_{m i}$ represent the phases of the electromagnetic torque, load torque and rotational speed, respectively.

In addition, the equation of the electromagnetic torque can also be expressed as

$$
T_{e}=k_{t} i_{q}
$$

where $k_{t}$ is the electromagnetic torque coefficient. Combining formulas (2)-(4) obtains:

$$
i_{q}=i_{q 0}+\sum_{i} i_{q i} \cos \left(2 \pi f_{i} t+\varphi_{q i}\right)
$$

where $i_{q 0}$ represents the mean value of the $\mathrm{q}$ axis current, and $\varphi_{q i}$ represents the phase of the $\mathrm{q}$ axis current. According to the principle of amplitude conservation, formula (5) can be obtained through inverse matrix transformation:

$$
\left[\begin{array}{c}
i_{a} \\
i_{b} \\
i_{c}
\end{array}\right]=\left[\begin{array}{cc}
\cos (\theta) & -\sin (\theta) \\
\cos \left(\theta-\frac{2}{3} \pi\right) & -\sin \left(\theta-\frac{2}{3} \pi\right) \\
\cos \left(\theta+\frac{2}{3} \pi\right) & -\sin \left(\theta+\frac{2}{3} \pi\right)
\end{array}\right]\left[\begin{array}{l}
i_{d} \\
i_{q}
\end{array}\right],
$$

The current in the $\mathrm{ABC}$ three-phase coordinate can be converted to a dq coordinate by formula (5), as shown in formula (6) [27]:

$$
\left\{\begin{array}{l}
i_{a}=-i_{q} \sin (\theta) \\
i_{b}=-i_{q} \sin \left(\theta-120^{\circ}\right) \\
i_{c}=-i_{q} \sin \left(\theta+120^{\circ}\right)
\end{array},\right.
$$

The position of the motor rotor can be obtained by formula (7):

$$
\theta=\theta_{0}+\int p \omega_{m} d t=\theta_{0}+p_{m 0} t+\sum_{i} \frac{p \omega_{m i}}{2 \pi f_{i}} \sin \left(2 \pi f_{i}+\varphi_{m i}\right)=\theta_{0}+2 \pi f_{e 0} t+\theta_{t z \prime}
$$


where $\theta_{0}$ represents the initial position of the rotor, $f_{e 0}$ represents the fundamental frequency of the current, $p$ represents the number of the motor poles, and $\theta_{t z}$ represents the modulation component of the angular velocity. Formula (8) can be obtained by combining formulas (4), (6) and (7):

$$
\begin{aligned}
& i_{a}=i_{q 0} \cos \left(2 \pi f_{e} t+\theta_{0}+\theta_{t z}+\frac{\pi}{2}\right) \\
& +\frac{1}{2} \sum_{i} i_{q i}\left[\cos \left(2 \pi\left(f_{e}+f_{i}\right) t+\varphi_{q i}+\theta_{0}+\theta_{t z}+\frac{\pi}{2}\right)+\cos \left(2 \pi\left(f_{e}-f_{i}\right) t-\varphi_{q i}+\theta_{0}+\theta_{t z}+\frac{\pi}{2}\right)\right]
\end{aligned}
$$

When there is a local fault in the reducer gear of the scraper conveyor, the fault position will generate a pulse signal $f(t)$ with frequency $f_{r}$ for the current signal, and $f_{r}$ is equal to the rotation frequency of the fault gear. According to formula (8), the fault pulse causes the frequency component $\left|f_{e} \pm f_{r}\right|$ in the current. If the signal satisfies the Dirichlet condition, it can be expanded into a Fourier series as formula (9):

$$
f(t)=\frac{a_{0}}{2}+\sum_{n=1}^{\infty} A_{n} \cos \left(2 \pi n f_{r} t+\varphi_{n}\right)
$$

where $\frac{a_{0}}{2}$ is the signal direct current (DC) component. It can be seen from equation 9 that the frequency doubled component $n f_{r}$ of the signal is generated by Fourier decomposition. Therefore, the local fault of the gear will result in the appearance of a component $\left|f_{e} \pm n f_{r}\right|,(n=1,2,3, \cdots)$ in the current spectrum $[17,28]$. BA can be defined as the 2-D Fourier Transform of the third-order cumulant (TOC) of the current signal, so fault characteristic frequency components also appear in the bispectrum spectrum.

\subsection{Current Preprocessing Method Based on WPMD and HT}

The current of the scraper conveyor is affected by the impact of coal flow load and scraper chain, and has the strong interference of fundamental frequency. These two factors lead to the weakening of fault characteristics in the current. Therefore, a current preprocessing method, which is based on WPMD and HT, is proposed to enhance the fault characteristics in the current.

WPMD is an effective signal-processing method [29,30]. Compared with wavelet analysis, WPMD is more precise in signal decomposition, avoiding the shortcomings of low high-frequency resolution. Once the orthogonal scale function $\varphi(x)$ and the wavelet function $\psi(x)$ are determined, the dual-scale equation can be derived:

$$
\left\{\begin{array}{l}
\varphi(x)=\sqrt{2} \sum_{k} h_{k} \varphi(2 x-k) \\
\psi(x)=\sqrt{2} \sum_{k} g_{k} \varphi(2 x-k)
\end{array},\right.
$$

where $h_{k}$ and $g_{k}$ represent a low-pass decomposition filter and a high-pass decomposition filter, respectively. A high frequency coefficient and a low frequency coefficient can be obtained by using the dual-scale equation. The essence of WPMD is to calculate the next layer decomposition coefficient by the current decomposition coefficient, which can be expressed as

$$
\left\{\begin{array}{l}
d_{l}^{2 i-1}=\sum_{k} h_{k-2 n} d_{l-1}^{i} \\
d_{l}^{2 i}=\sum_{k} g_{k-2 n} d_{l-1}^{i}
\end{array},\right.
$$

where $d_{l}^{i}$ represents the $i-t h$ WPMD coefficient in the $j-$ th layer. The $2^{N}$ frequency bands can be obtained by the $\mathrm{N}$-layer decomposition of the current. If the sampling frequency is $f_{s}$ and a subspace of the $j$-th layer is $(i, j)$, then the frequency range of the subspace can be expressed as $\left[\frac{f_{s}}{2^{N-i+1}} \times j, \frac{f_{s}}{2^{N-i+1}} \times(j+1)\right]$. Assuming that the subspace is a gear fault frequency band $x(t)$, it can be 
extracted by filtering out the impulse signal irrelevant to the fault from the full frequency band signal. After the amplitude demodulation of $x(t)$ by HT, the signal $y(t)$ is obtained. $y(t)$ can be expressed as

$$
y(t)=x(t) * \frac{1}{\pi}=\frac{1}{\pi} \int_{-\infty}^{+\infty} \frac{x(\tau)}{t-\tau} d \tau,
$$

After the HT of the fault frequency band signal $x(t)$, the positive frequency component will undergo a $-90^{\circ}$ phase shift, while the negative frequency component will undergo a $+90^{\circ}$ phase shift. Taking $x(t)$ as the real part and $y(t)$ as the imaginary part, the analytical signal of the fault frequency band $z(t)$ can be constructed jointly, which can be expressed as

$$
z(t)=x(t)+j y(t)
$$

The envelope $e(t)$ can be obtained by taking the absolute value of the analytical signal, which can be expressed as

$$
e(t)=|x(t)+j y(t)|=\sqrt{x^{2}(t)+y^{2}(t)},
$$

The significance of the amplitude demodulation for the fault frequency band is to eliminate the interference of the current fundamental frequency.

\subsection{The Fault Feature Extraction Based on BA}

Compared with traditional signal-processing methods, BA has the characteristics of good nonlinear identification, the elimination of Gaussian noise, and the retention of phase information. Therefore, BA is a very effective method for processing current signals. For the envelope signal of the fault band, BA can be defined as the 2-D Fourier Transform of its TOC. The TOC can be expressed as

$$
c_{3 x}\left(\tau_{1}, \tau_{2}\right)=E\left(e(i) e\left(i+\tau_{1}\right) e\left(i+\tau_{1}\right)\right),
$$

where $\tau$ is the time delay and $E()$ is the function to solve the expectation. If the TOC $c_{3 x}\left(\tau_{1}, \tau_{2}\right)$ satisfies formula (16), the bispectrum statistical result can be expressed as formula (17):

$$
\begin{gathered}
\sum_{\tau_{1}=-\infty}^{\infty} \sum_{\tau_{2}=-\infty}^{\infty} c_{3 x}\left(\tau_{1}, \tau_{2}\right)<\infty, \\
B_{x}\left(\omega_{1}, \omega_{2}\right)=\sum_{\tau_{1}=-\infty}^{\infty} \sum_{\tau_{2}=-\infty}^{\infty} c_{3 x}\left(\tau_{1}, \tau_{2}\right) \exp \left[-j\left(\omega_{1} \tau_{1}+\omega_{2} \tau_{2}\right)\right],
\end{gathered}
$$

where $\omega$ is the frequency parameter and satisfies $\left|\omega_{1}\right| \leq \pi,\left|\omega_{2}\right| \leq \pi$ and $\left|\omega_{1}+\omega_{2}\right| \leq \pi$. From Section 2.1, we know that the gear fault characteristic frequency is $\left|f_{e} \pm n f_{r}\right|$, and this characteristic frequency will appear in $B_{x}\left(\omega_{1}, \omega_{2}\right)$ when the gear has a partial failure.

$\mathrm{BE}$ can reflect the energy distribution in the current, which is affected by gear failure. Therefore, using $\mathrm{BE}$ as an indicator can effectively analyze the strength of the fault signal in the current under time-varying load conditions. Solving amplitude probability is the first step to obtain BE. The probability of amplitude $P_{B}\left(\omega_{1}, \omega_{2}\right)$ can be expressed as

$$
P_{B}\left(\omega_{1}, \omega_{2}\right)=\frac{\left|B_{x}\left(\omega_{1}, \omega_{2}\right)\right|}{\sum_{\omega_{1}=0}^{\pi} \sum_{\omega_{2}=0}^{\pi}\left|B_{x}\left(\omega_{1}, \omega_{2}\right)\right|},
$$


where $\sum_{\omega_{1}=0}^{\pi} \sum_{\omega_{2}=0}^{\pi}\left|B_{x}\left(\omega_{1}, \omega_{2}\right)\right|$ represents the characteristic value of non-Gaussian intensity. BE $H_{B}$ can be expressed as

$$
H_{B}=-\sum_{\omega_{1}=0}^{\pi} \sum_{\omega_{2}=0}^{\pi} P_{B}\left(\omega_{1}, \omega_{2}\right) \ln P_{B}\left(\omega_{1}, \omega_{2}\right)
$$

When the energy distribution in the signal is more uniform, the BE is larger, otherwise it is smaller. Usually, the fault signal can make the energy distribution in the current more concentrated, so the BE is larger when the fault signal is stronger.

\section{Experiment}

\subsection{Experimental Equipment}

Taking the actual coal mining process as the research background, the fault diagnosis method proposed in this paper was verified on the scraper conveyor reducer of HB-kpl-75. The reducer used in this experiment is shown in Figure 5, and its internal transmission chain is shown in Figure 6.

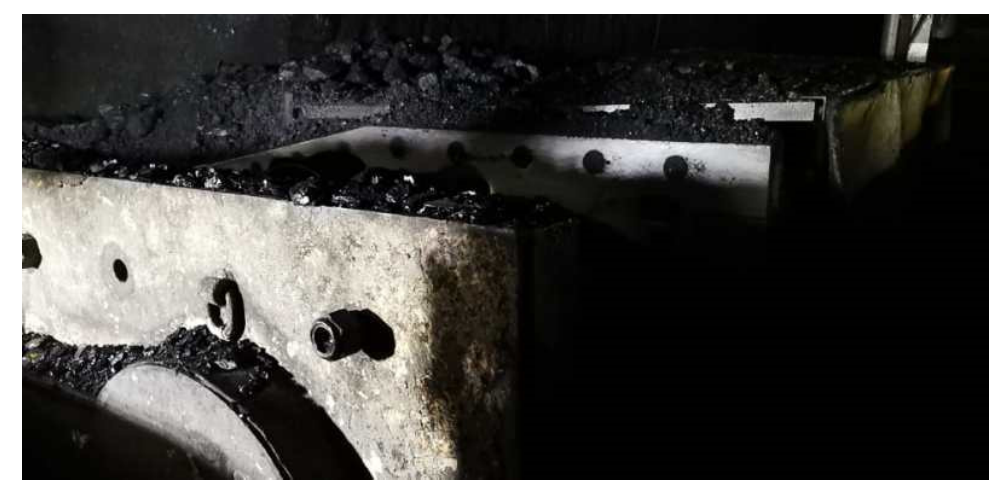

Figure 5. Hb-kpl-75 reducer.

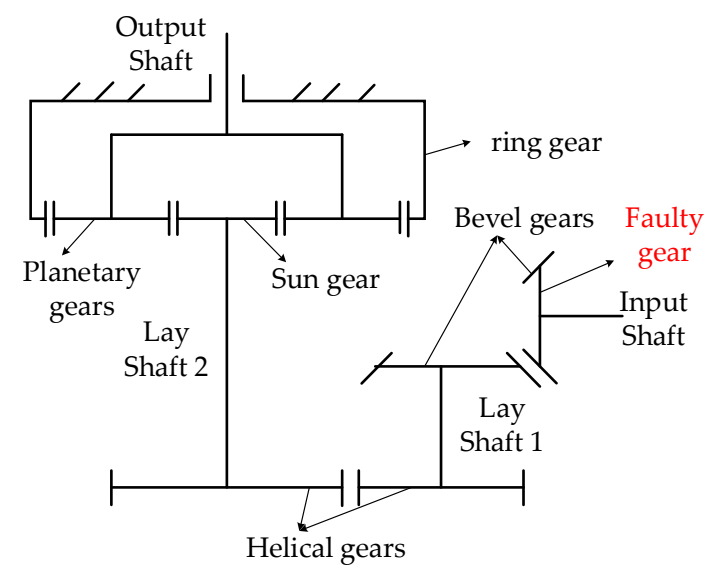

Figure 6. The transmission chain of the $\mathrm{Hb}-\mathrm{kpl}-75$ reducer.

Some parameters of the reducer are shown in Table 1.

Table 1. Some parameters of the reducer.

\begin{tabular}{cccc}
\hline Input Rotate Speed (r/min) & Mass (kg) & Power (Kw) & Rotating Frequency of Faulty Gear (Hz) \\
\hline 1400 & 8150 & 1500 & 23.3 \\
\hline
\end{tabular}


The fundamental frequency of the current and the rotating frequency of the faulty gear are $50 \mathrm{~Hz}$ and $23.3 \mathrm{~Hz}$, respectively. According to Section 2.1, it can be known that the characteristic frequency of the faulty gear can be determined as $|50 \mathrm{~Hz} \pm n 23.3 \mathrm{~Hz}|$. The following is the experimental process of this article.

\subsection{Acquisition of Stator Current}

The scraper conveyor constitutes low-speed and heavy-load machinery, and its working current often reaches several hundred amperes. It is very dangerous to collect large current directly. Therefore, this paper converts the large current to the small current through the current transformer, and then collects the converted three-phase current through the acquisition card. The current sampling frequency is $10 \mathrm{KHz}$. In order to improve the resolution of the acquisition, this article uses a 24-bit acquisition card. Before the acquisition, the current is anti-aliased to eliminate the frequency aliasing. The current collection position is inside the vacuum power supply switch, and the collection device is shown in Figures 7-9; representing the A-phase current of the motor under normal and faulty conditions, respectively. It can be seen from Figures 8 and 9 that the stator current of the scraper conveyor increases with time, which means that the load of the scraper conveyor increases gradually during this period.

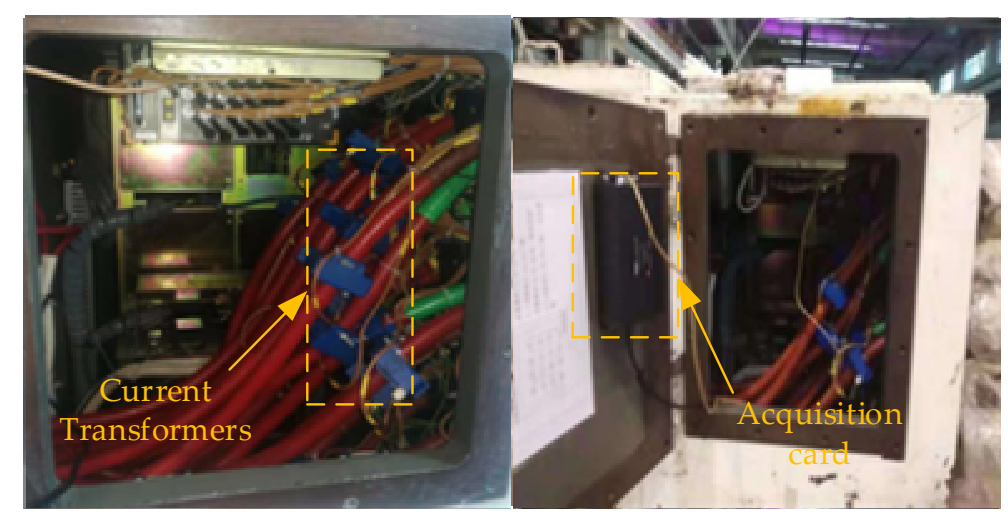

Figure 7. Current collection device of the scraper conveyor.

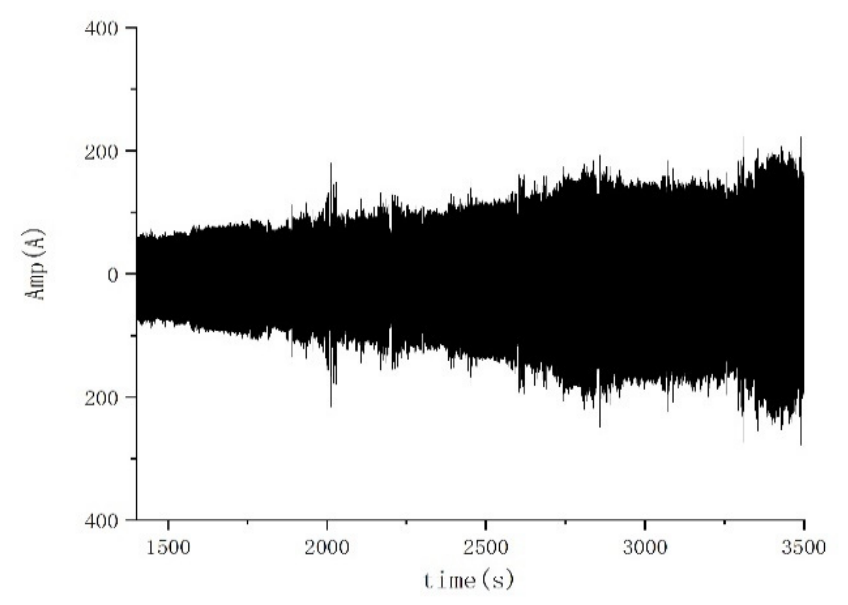

Figure 8. The A-phase current of the motor under normal conditions. 


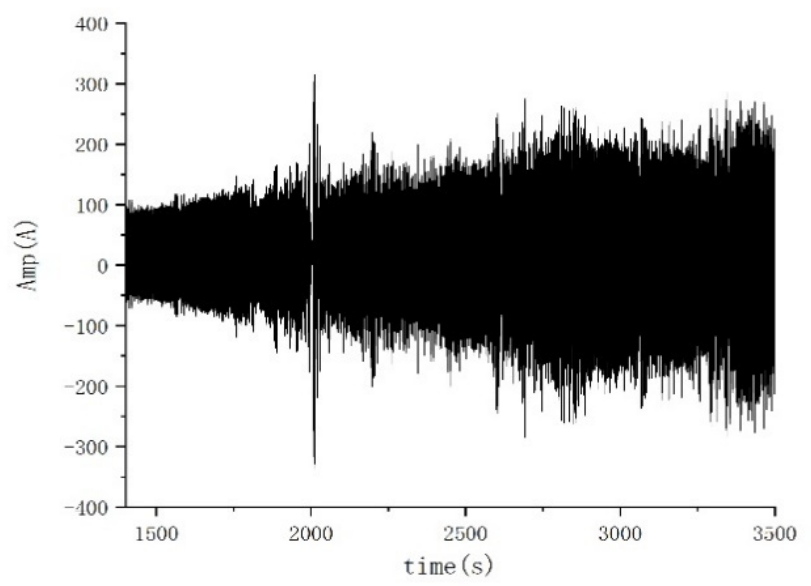

Figure 9. The A-phase current of the motor under faulty conditions.

This article intends to use the magnitude of the current to characterize the load. It can be seen from Figure 9 that the peak value of the fault current continuously increases from $90 \mathrm{~A}$ to $280 \mathrm{~A}$ over time, which means that the load of the scraper conveyor keeps increasing. In the process of the current changing from $90 \mathrm{~A}$ to $280 \mathrm{~A}$, a period of two seconds of current signal was taken at every $38 \mathrm{~A}$ interval, and then six signals with current peaks of 90A, 128A, 166A, 204A, 242A and 280A were obtained, respectively, as shown in Figure 10.

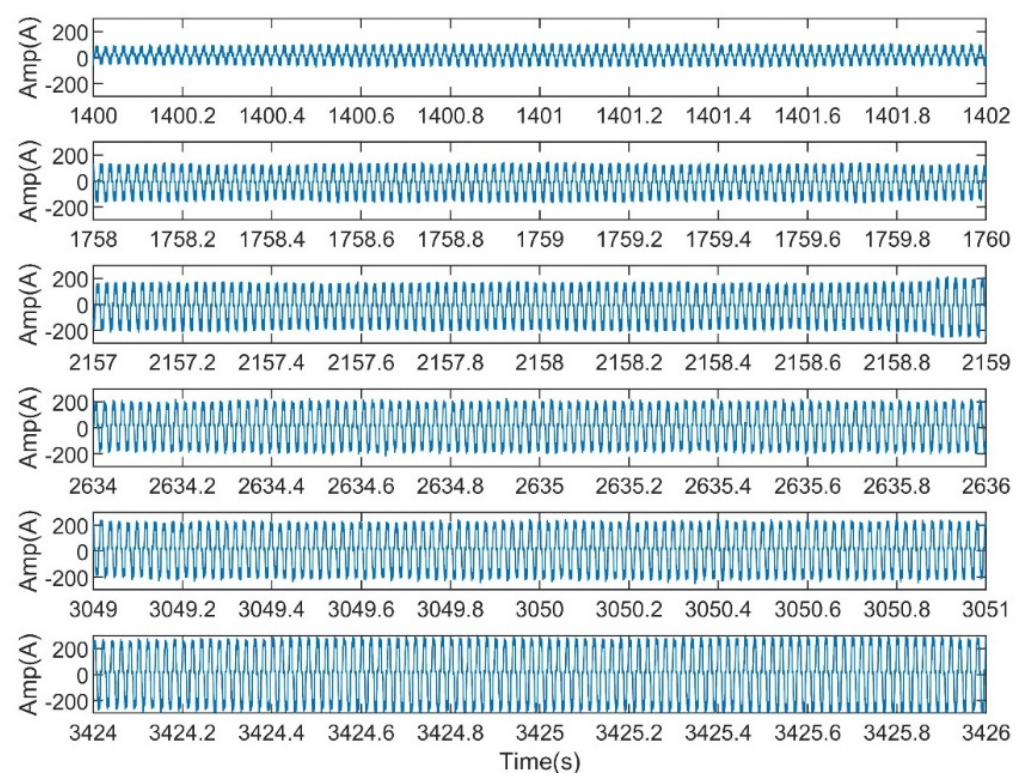

Figure 10. Gear fault current under the different load conditions.

\subsection{The Programme of the Proposed Fault Diagnosis Method}

The work of this experiment mainly includes the current preprocessing, the extraction of the gear fault frequency and fault analysis. The experimental scheme is shown in Figure 11. 


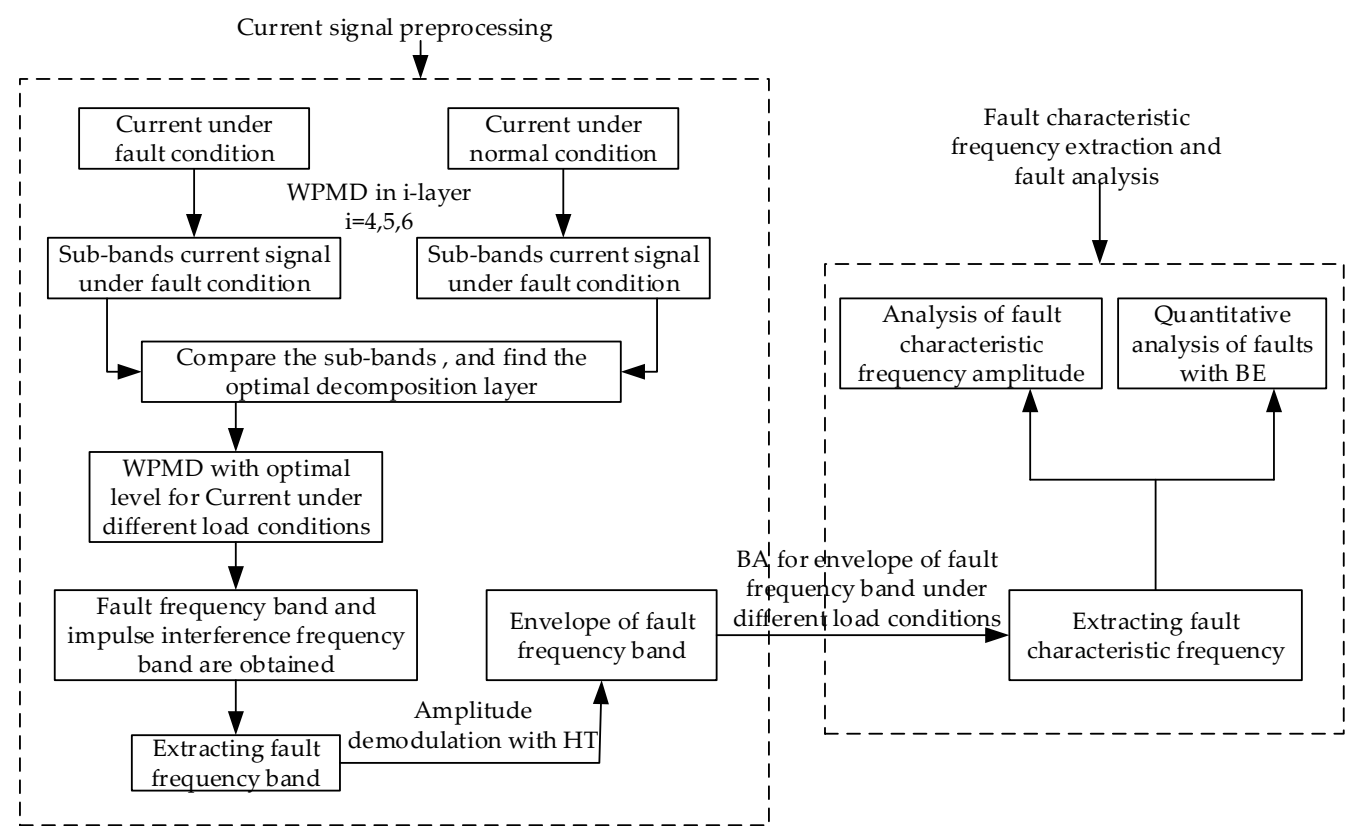

Figure 11. The experimental scheme.

In current preprocessing, both the fault current and normal current were processed by WPMD in four layers, five layers and six layers, so the currents were decomposed into a series of sub-bands. Then, the sub-bands under normal and faulty conditions were compared to determine the optimal decomposition layer. Then, the WPMD was carried out for the fault currents under the different load conditions with the optimal decomposition layer, and the fault frequency band was extracted from the obtained sub-band signal, so as to eliminate the impact interference of the coal flow load and scraper chain. Finally, the HT was used to demodulate the amplitude of the fault frequency signal to eliminate the interference of the fundamental frequency of the current, so as to enhance the frequency component of the gear fault.

After the current preprocessing, the fault characteristic frequency of the gear under different load conditions was extracted by BA. Then, the characteristic frequency amplitude under different load conditions was counted, and the BE was used to realize the quantitative analysis of the gear fault.

\section{Results and Discussion}

\subsection{Preprocessing of Stator Current}

The current signal preprocessing included two parts: extracting the fault frequency band and suppressing the fundamental frequency interference.

\subsubsection{Extraction of Fault Frequency Band}

The faulty current with a peak value of $280 \mathrm{~A}$ was taken as an example for analysis to find the optimal decomposition layer in our paper. Both the fault current and normal current were processed by WPMD in four layer, five layers and six layers, and finally $2^{4}, 2^{5}$ and $2^{6}$ frequency bands were obtained, respectively. Considering that the current fault frequency was mainly distributed in the low frequency component around the current fundamental frequency, it was only necessary to analyze the first four frequency bands obtained by WPMD under normal and faulty conditions. The results obtained under the three decomposition layers are shown in Figures 12-14, respectively. 


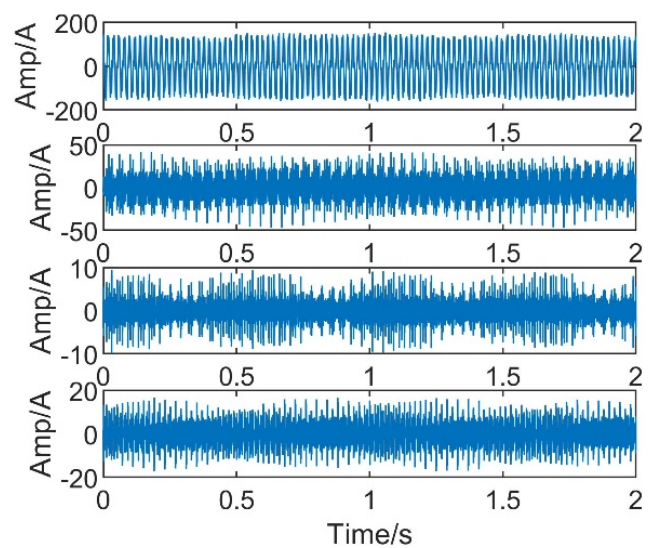

(a)

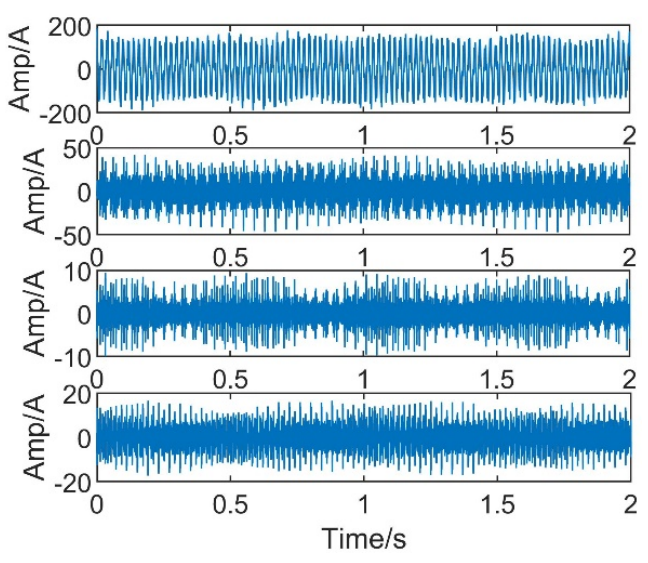

(b)

Figure 12. The first four frequency bands from the four-layer decomposition: (a) the current under normal working conditions; and (b) the current under faulty working conditions.

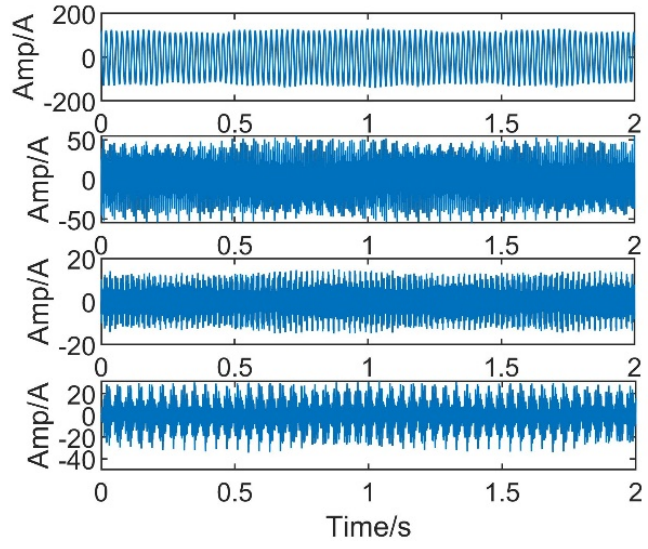

(a)

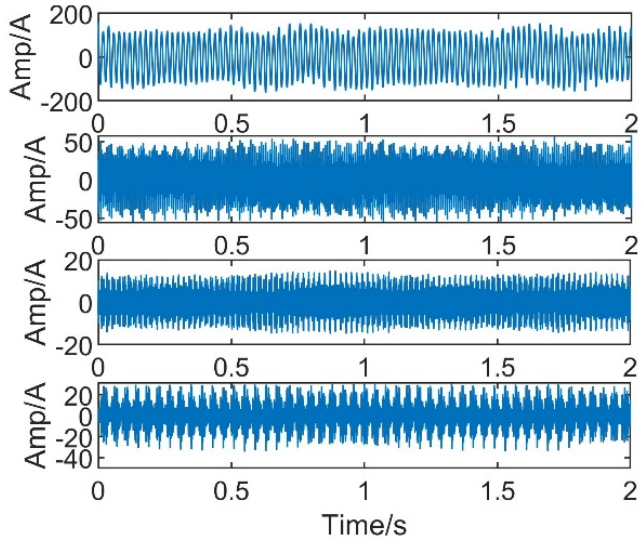

(b)

Figure 13. The first four frequency bands from the five-layer decomposition: (a) the current under normal working conditions; and (b) the current under faulty working conditions.
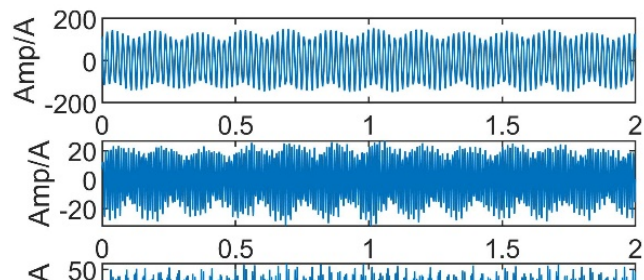

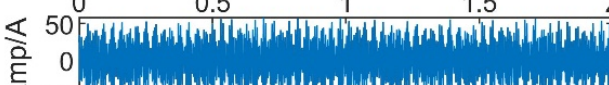

远 $\begin{array}{r}0 \\ -50\end{array}$

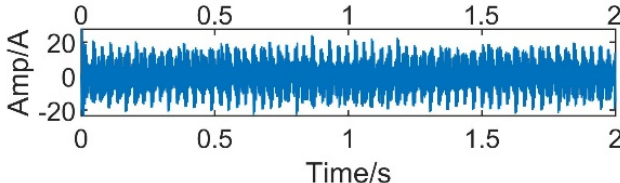

(a)

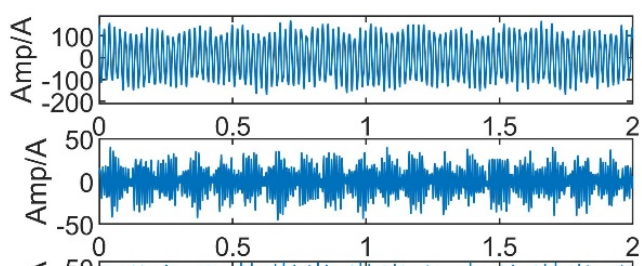

$\leqslant 50$ (w)

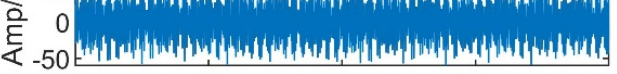

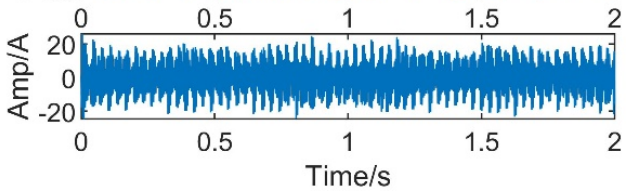

(b)

Figure 14. The first four frequency bands from the six-layer decomposition: (a) the current under normal working conditions; and (b) the current under faulty working conditions. 
Comparing Figure 12a,b, Figure 13a,b, it can be found that when the current was decomposed into four layers and five layers, the first frequency band of the current under normal and faulty conditions is significantly different, which indicates that the fault signal is concentrated in the first frequency band. Comparing Figure 14a,b, it can be found that when the current is decomposed into six layers, the first two frequency bands of the fault current have changed compared to the normal current, which indicates the distribution of fault signals in the first two frequency bands. Tables 2-4 are the ranges of the first four frequency bands obtained when the current was decomposed in four layers, five layers and six layers, respectively. It can be seen from Table 2, that when the current was decomposed in four layers, the fault frequency range was $0-312.5 \mathrm{~Hz}$. It can be seen from Table 3, that when the current was decomposed in five layers, the fault frequency range was $0-156.3 \mathrm{~Hz}$, which was shortened by half compared to the four-layer decomposition, thereby improving the accuracy of extracting the fault frequency band. It can be seen from Table 4, that when the current was decomposed in six layers, the fault frequency band included $0-78.2 \mathrm{~Hz}$ and $78.2-156.3 \mathrm{~Hz}$. At this time, because the fault signal was decomposed into two frequency bands, it was not conducive to the extraction of the fault frequency band.

Table 2. Frequency band of the current signal under 4-layer decomposition.

\begin{tabular}{cc}
\hline Frequency Band Number & Range of Frequency Band \\
\hline 1 & $0-312.5 \mathrm{~Hz}$ \\
2 & $312.5-625 \mathrm{~Hz}$ \\
3 & $625-937.5 \mathrm{~Hz}$ \\
4 & $937.5-1250 \mathrm{~Hz}$ \\
\hline
\end{tabular}

Table 3. Frequency band of the current signal under 5-layer decomposition.

\begin{tabular}{cc}
\hline Frequency Band Number & Range of Frequency Band \\
\hline 1 & $0-156.3 \mathrm{~Hz}$ \\
2 & $156.3-312.5 \mathrm{~Hz}$ \\
3 & $312.5-468.8 \mathrm{~Hz}$ \\
4 & $468.8-625 \mathrm{~Hz}$ \\
\hline
\end{tabular}

Table 4. Frequency band of the current signal under 6-layer decomposition.

\begin{tabular}{cc}
\hline Frequency Band Number & Range of Frequency Band \\
\hline 1 & $0-78.2 \mathrm{~Hz}$ \\
2 & $78.2-156.3 \mathrm{~Hz}$ \\
3 & $156.3-234.5 \mathrm{~Hz}$ \\
4 & $234.5-312.5 \mathrm{~Hz}$ \\
\hline
\end{tabular}

Based on the above analysis, the following conclusions can be drawn: when the number of decomposition layers is less than five, the signal decomposition is not accurate enough, at this time, and the extracted fault frequency band may be mixed with the impact signal of the coal flow and scraper chain; when the amount of decomposition layers is more than five layers, it will cause the dispersion of the fault frequency band. When the number of decomposition layers is equal to five layers, all the fault information is concentrated in one frequency band, and the impact interference of coal flow and scraper can be removed to the greatest extent. Therefore, the optimal number of decomposition layers of the current signal is five layers. The first frequency band signal obtained when the current was decomposed in five layers was the fault frequency band signal we expected to extract.

\subsubsection{Amplitude Demodulation of Fault Frequency Band}

After finding the optimal decomposition layer, the fault currents with peak values of 90A, 128A, $166 \mathrm{~A}, 204 \mathrm{~A}, 242 \mathrm{~A}$ and $280 \mathrm{~A}$ were decomposed in five layers to extract the fault frequency bands under 
different load conditions. Then, the amplitude of these fault frequency bands were demodulated with HT. The six extracted fault band signals and their envelopes are shown in Figure 15. In order to verify the effect of the current preprocessing, the original fault current with an amplitude of $280 \mathrm{~A}$ and the preprocessed signal were analyzed by time-frequency analysis. The results are shown in Figure 16. From Figure 16a, it can be seen that there is an obvious $50 \mathrm{~Hz}$ fundamental frequency component in the current without preprocessing, and the gear failure component is not obvious. It can be seen from Figure $16 \mathrm{~b}$ that after the original current signal is preprocessed, the fault component around the current fundamental frequency in the current is obviously enhanced.

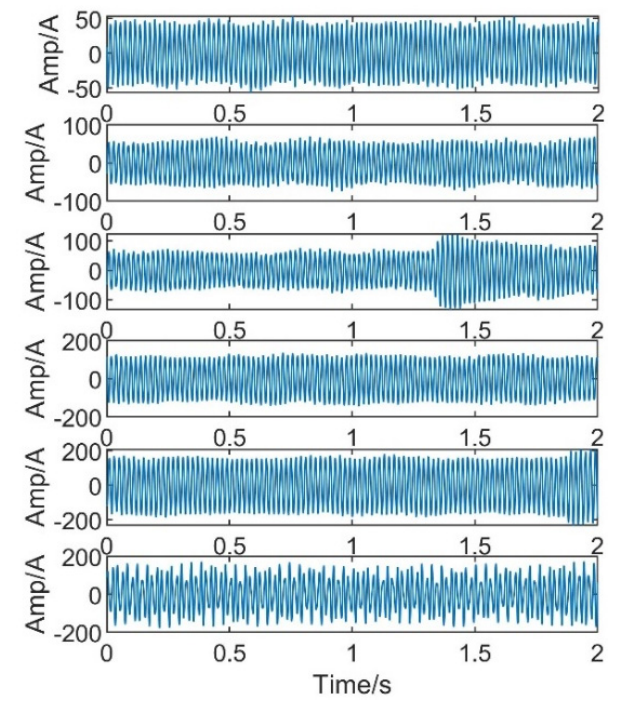

(a)

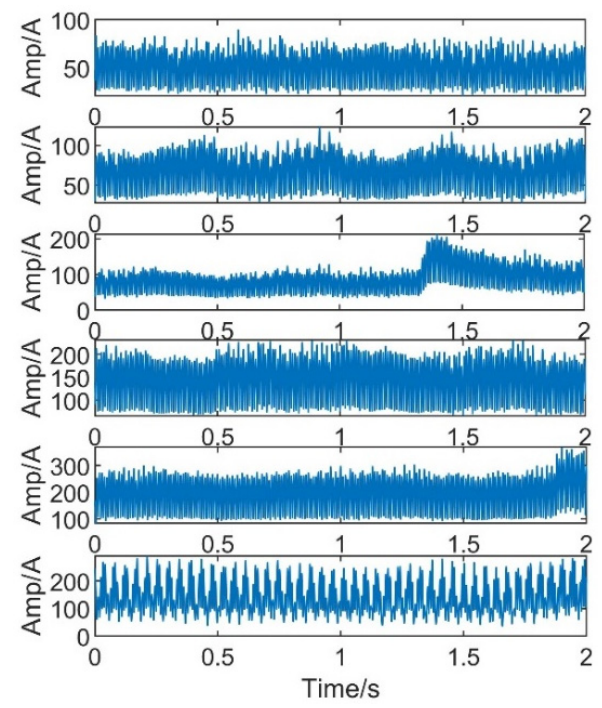

(b)

Figure 15. Fault frequency band signals and their envelope under time-varying load conditions: (a) the fault frequency band signals; and (b) the envelope of the fault frequency band signals.

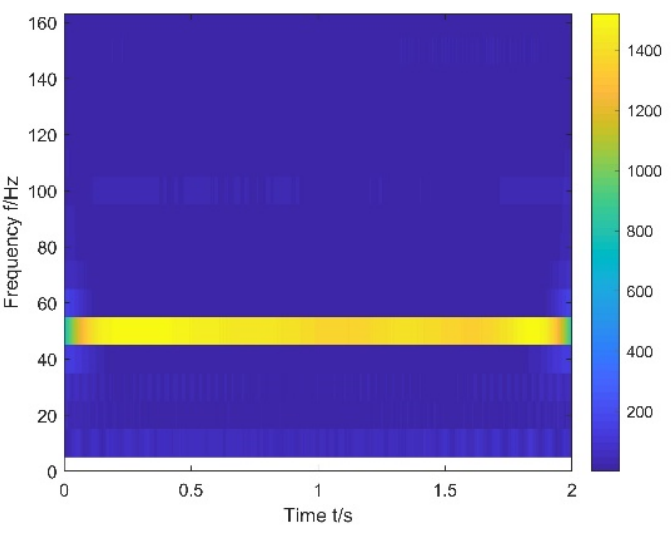

(a)

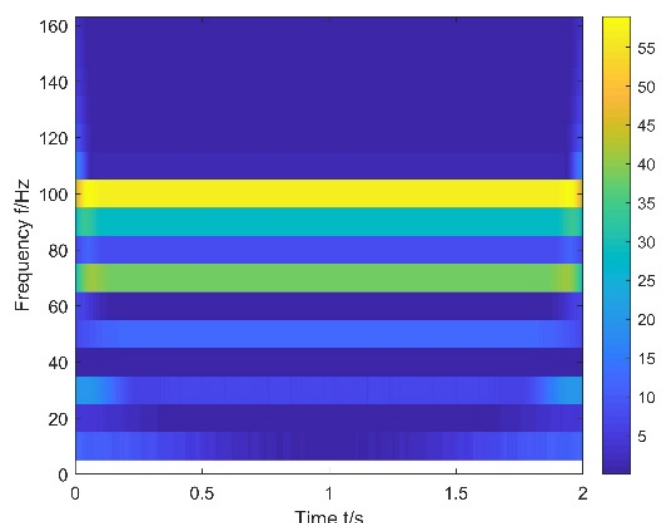

(b)

Figure 16. Time-frequency analysis of the load current with a peak value of 280A: (a) the original current; and (b) the preprocessed signal.

\subsection{Fault Characteristic Frequency Extraction and Fault Analysis}

Figures 17-22 are the BA spectrum and the bispectrum slice (BS) of the fault band envelope of the currents with peak values of 90A, 128A, 166A, 204A, 242A and 280A, respectively. By comparing the BA spectra under different load conditions, it can be found that there are obvious characteristic frequencies of gear failure $(3.4 \mathrm{~Hz}, 26.4 \mathrm{~Hz}, 73.3 \mathrm{~Hz}$ and $96.6 \mathrm{~Hz})$ in each figure. As mentioned in 
Section 3.1, the characteristic frequency of the gear failure is $|50 \pm n 23.3| \mathrm{Hz}$, and these four peaks correspond to the characteristic frequencies when $\mathrm{n}$ is equal to 1 or 2, respectively. The location of these fault frequencies is marked in the figure. Because of the symmetry of the BA results, only half of the area was marked. The BS spectrum was obtained by taking a section along the distribution of the fault frequency in the BA spectrum. The purpose of the slice was to observe the change in the fault characteristic frequency more conveniently.

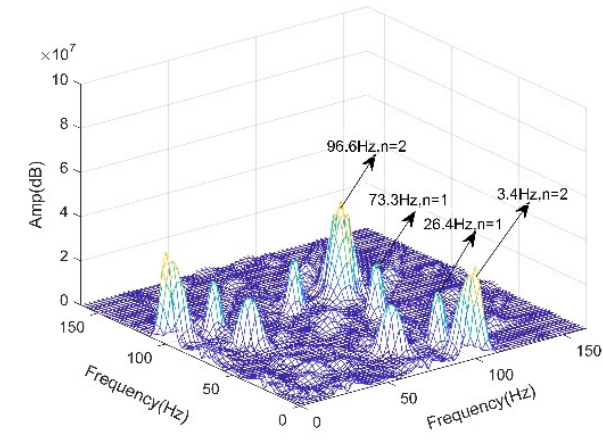

(a)

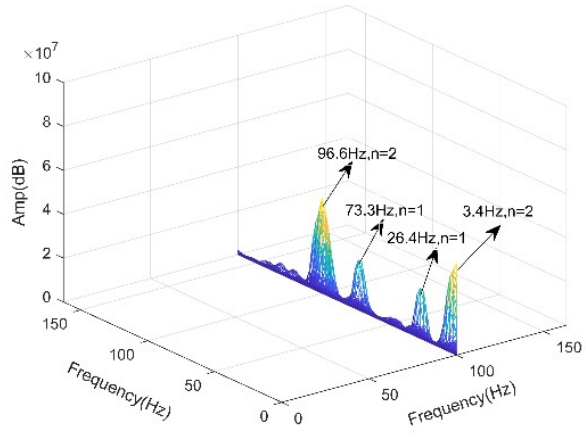

(b)

Figure 17. Characteristic frequency of the gear failure under a current peak of 90A: (a) the result of the BA; and (b) the bispectrum slice (BS).

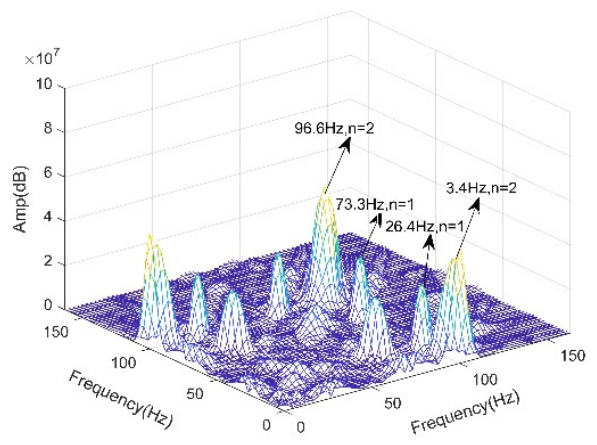

(a)

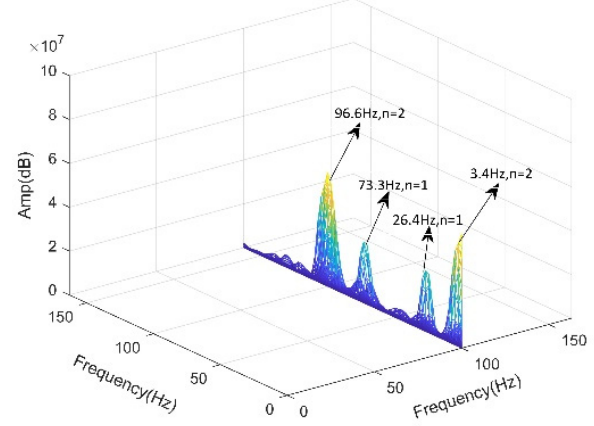

(b)

Figure 18. Characteristic frequency of the gear failure under a current peak of 128A: (a) the result of the BA; and (b) the BS.

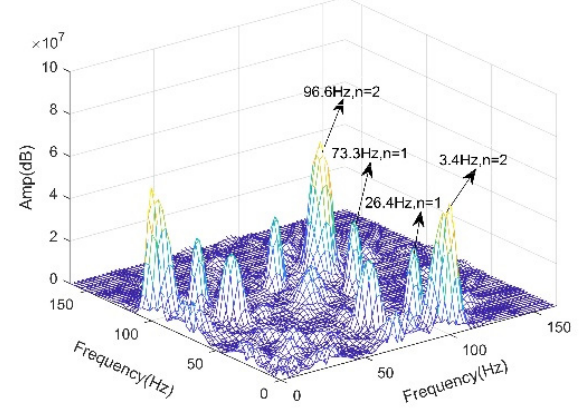

(a)

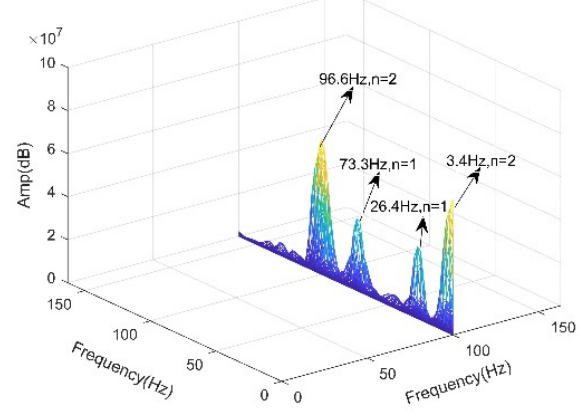

(b)

Figure 19. Characteristic frequency of the gear failure under a current peak of 166A: (a) the result of the BA; and (b) the BS. 


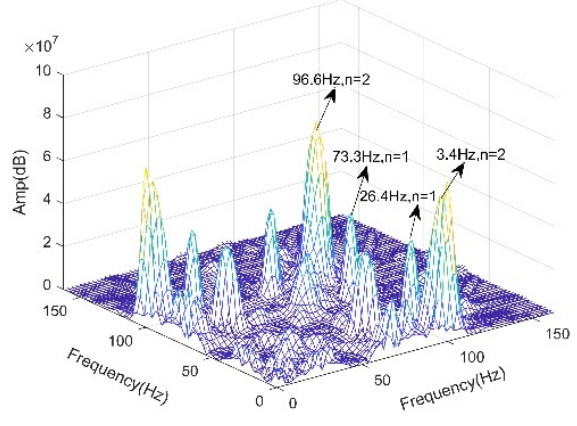

(a)

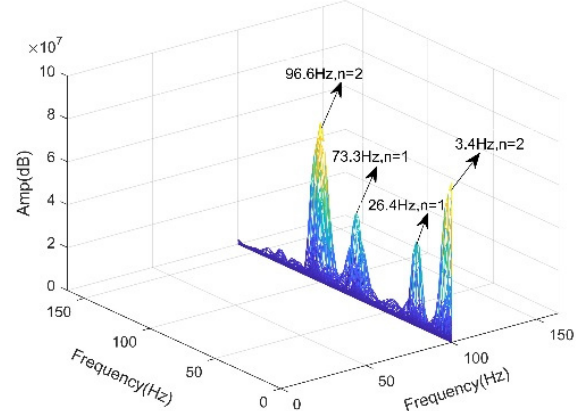

(b)

Figure 20. Characteristic frequency of the gear failure under a current peak of 204A: (a) the result of the BA; and (b) the BS.

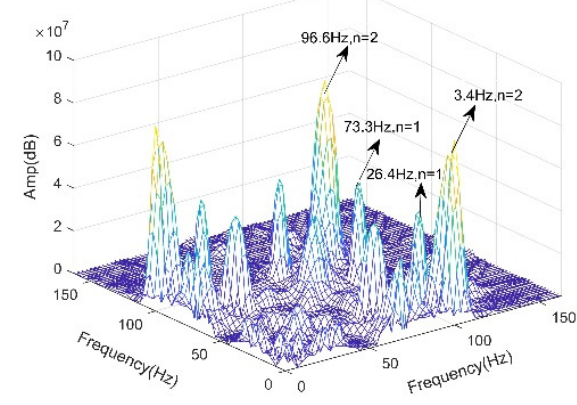

(a)

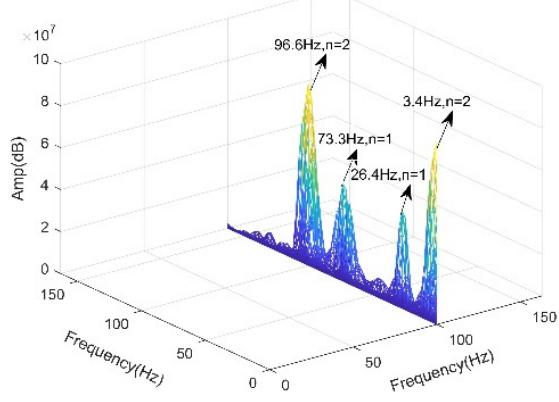

(b)

Figure 21. Characteristic frequency of the gear failure under a current peak of 242A: (a) the result of the BA; and (b) the BS.

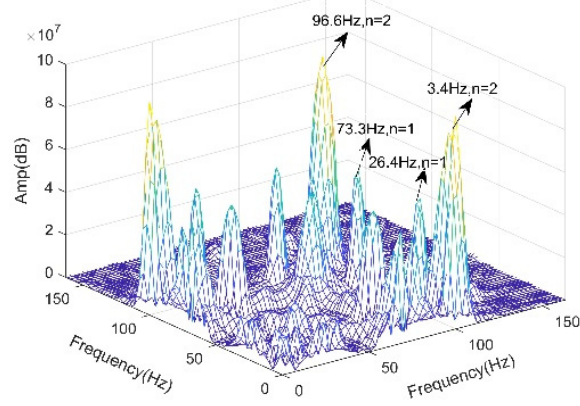

(a)

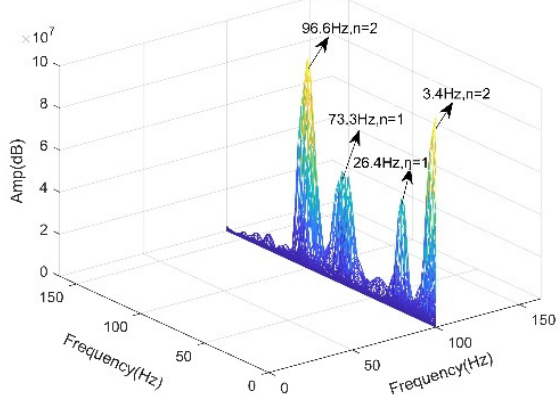

(b)

Figure 22. Characteristic frequency of the gear failure under a current peak of 280A: (a) the result of the BA; and (b) the BS.

In the process of the load current peak changing from $90 \mathrm{~A}$ to $280 \mathrm{~A}$, the magnitude of the fault frequency in the BA spectrum did not change, but the amplitude of the fault frequency increased continuously. The reducer of the scraper conveyor always keeps a relatively constant output speed during operation, and the gear failure frequency can be controlled by the motor speed, so the gear failure frequency does not change with the load. The increasing amplitude of the fault characteristic 
frequency indicates that the load condition had obvious influence on the fault information of the gear in the current.

Figure 23 is the change in the fault frequency amplitude under the time-varying load conditions. From Figure 23, it can be seen that the peak value of the fault characteristic frequency increases with the increase in the load. This shows that when the load increases, the fault frequency component in the current is stronger. However, the characteristic frequency amplitude can only qualitatively analyze the strength of the fault information in the current, and cannot quantitatively analyze the impact of the load from the energy perspective. Gear failure can cause the energy distribution in the current to be concentrated, which reduces the BE of the current. Therefore, using BE as an indicator can achieve the quantitative analysis of gear failures. The BE under time-varying load conditions is shown in Figure 24, and the BE under different load conditions was 10.84, 14.71, 10.65, 10.49, 10.35 and 10.15, respectively. Obviously, the BE decreases with the increase in the load. The smaller the BE is, the more the energy in the current is concentrated. The gear fault can make the energy in the current mainly concentrated in the local frequency band, so the smaller BE indirectly reflects that the fault signal in the current is more intense as the load increases.

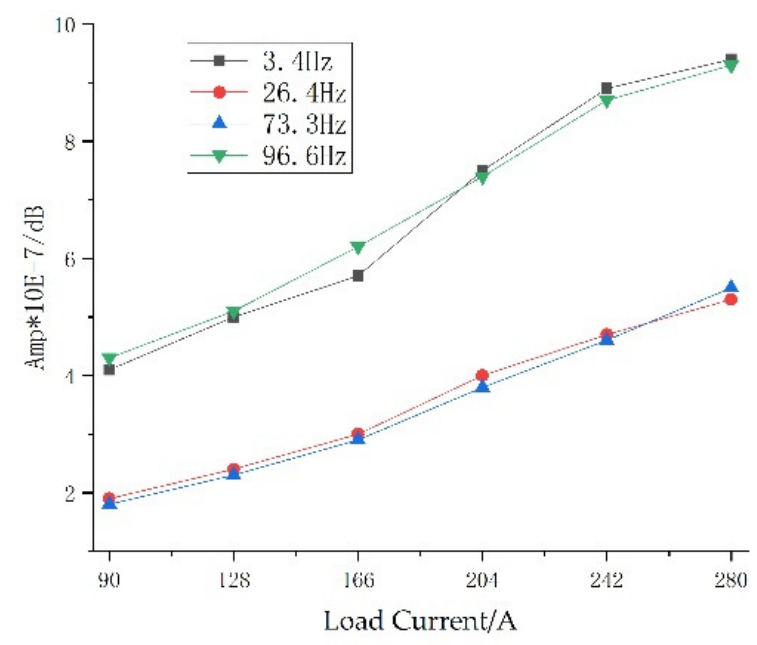

Figure 23. Amplitude change of the fault characteristic frequency under the time-varying load.

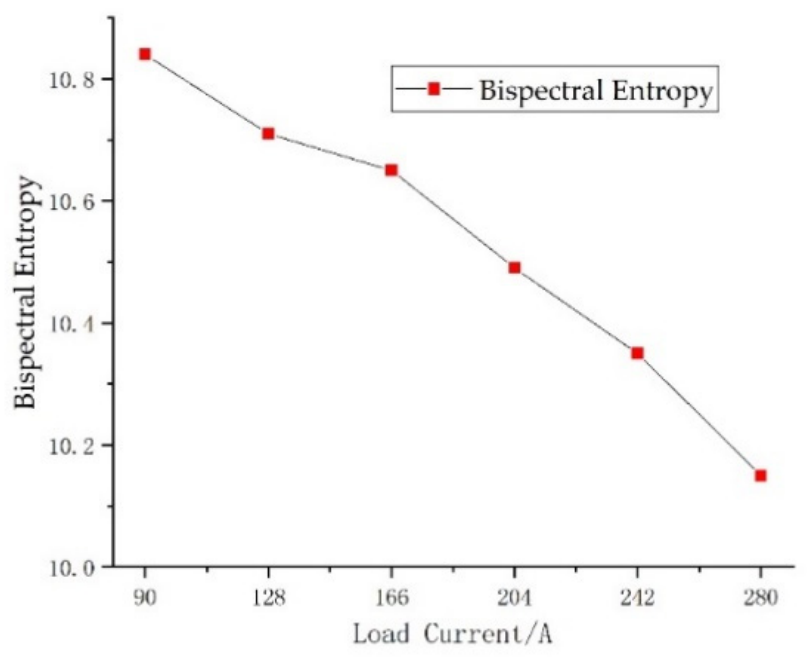

Figure 24. The change of the BE under the time-varying load.

In addition, a gear fault diagnosis method based on current spectrum analysis is proposed in reference [31], which is compared with the method proposed in our paper. The spectrums of the current under different load conditions are shown in Figure 25. 


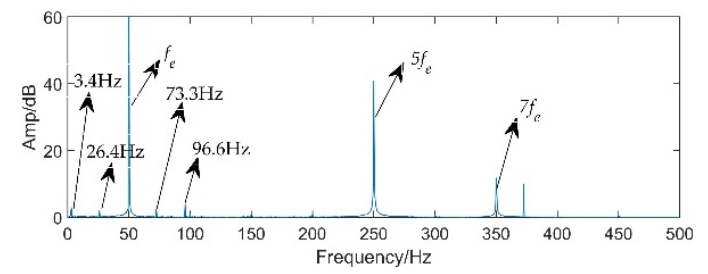

(a)

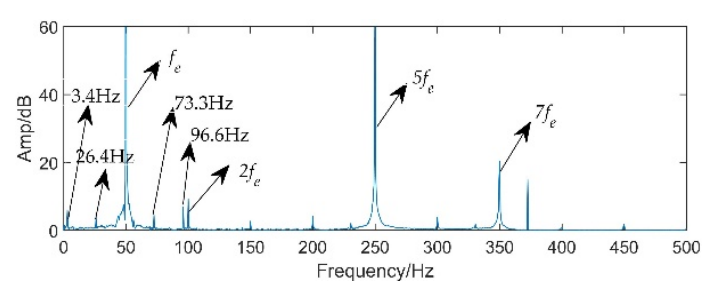

(c)

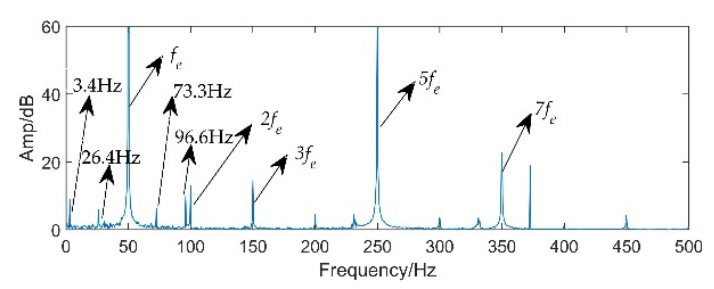

(e)

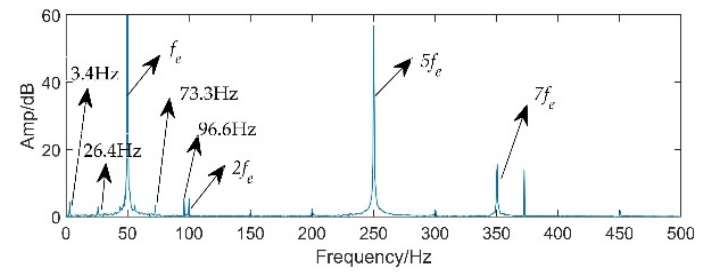

(b)

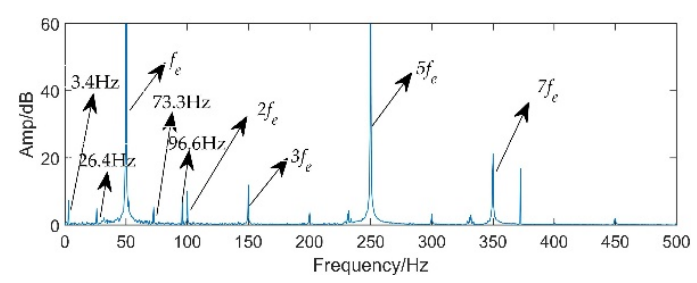

(d)

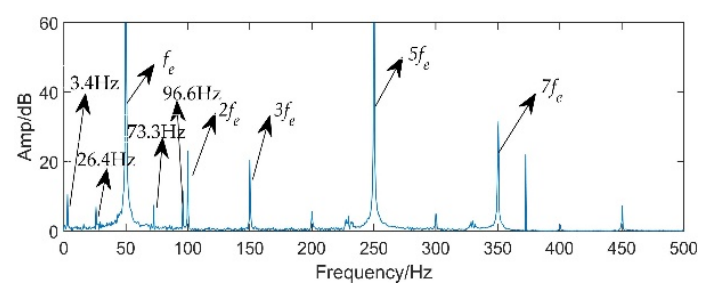

$(\mathbf{f})$

Figure 25. Current spectrum under the different load conditions: (a) the 90A peak current; (b) the 128A peak current; (c) the 166A peak current; (d) the 204A peak current; (e) the 242A peak current; and (f) the $280 \mathrm{~A}$ peak current.

In Figure 25, $f_{e}$ represents the current fundamental frequency. It can be seen from Figure 25 that the characteristic frequencies of gear fault under different load conditions are seriously weakened by the current fundamental frequency and their frequency multiplication. Although the amplitude of the gear failure frequency increases as the load increases, the characteristic frequency of the failure is still weak relative to the current fundamental frequency, even at the highest load. In addition, the characteristic frequency of the gear faults is distributed at low frequencies in the current spectrums, but there are high-frequency shock components that are not related to the fault. These high-frequency signals also affect the extraction of gear failure frequencies. Therefore, the method based on the frequency spectrum analysis is not good for the diagnosis of the scraper conveyor gear. The method proposed in our paper can eliminate the interference of the fundamental frequency and the impact signal unrelated to the fault, and is more suitable for the diagnosis of the scraper conveyor gear fault.

\section{Conclusions}

A fault diagnosis method, which was based on the BA of the stator current analytical signal envelope, is proposed in our paper. The proposed method is verified on the scraper conveyor reducer model HB-kpl-75. The main conclusions are as follows:

1. The interference of fundamental frequency and impact signal in the current will seriously weaken the gear fault characteristics. The proposed current preprocessing method, which is based on the WPMD and HT, is used to enhance the fault characteristics. When the current signal is decomposed in five layers, the best extraction of the fault frequency band can be achieved, and the 
effect of eliminating the impact interference is optimal. The extracted best fault frequency band is processed by HT, thus the fundamental frequency of the current can be suppressed.

2. The fault characteristic frequency of the gear is extracted successfully by BA, and the quantitative analysis of the fault under time-varying load conditions is realized with BE. With the increase in the load, the BE is $10.84,14.71,10.65,10.49,10.35$ and 10.15 , respectively. Obviously, the BE decreases with the increase in the load. The decrease in the BE indirectly reflects that the fault signal in the current is more intense with the increase in the load.

Author Contributions: Conceptualization, S.Z.; formal analysis, P.W.; methodology, S.Z. and P.W.; project administration, S.Z.; resources, S.Z. and S.L.; software, P.W.; supervision, S.L.; validation, P.W.; writing-original draft, P.W.; writing-review and editing, P.W. All authors have read and agreed to the published version of the manuscript.

Funding: This research was funded by the National key Research and Development Program (Project NO.2017YFC0804310) and Shaanxi Provincial Key Research and Development Program (Project NO.S2020-YF-ZDCXL-ZDLGY-0295) and Shaanxi province special project of technological innovation guidance (fund) (Program No.2019QYPY-055) and Key Research and development plan of Shaanxi Province (Project NO. S2020-YF-ZDCXL-ZDLGY-0226) and the Shaanxi Province key Research and Development Program (Project NO.2019ZDLGY03-09-02) and Shaanxi Provincial Education Department serves Local Scientific Research Plan in 2019 (Project NO.19JC028) and Shaanxi Provincial Key Research and Development Program (Project NO.2018ZDCXL-G-13-9).

Conflicts of Interest: The authors declare no conflict of interest.

\section{References}

1. Wu, T.Y.; Chen, J.C.; Wang, C.C. Characterization of Gear Faults in Variable Rotating Speed Using Hilbert-Huang Transform and Instantaneous Dimensionless Frequency Normalization. Mech. Syst. Signal. Process. 2012, 30, 103-122. [CrossRef]

2. Chinmaya, K.; Mohanty, A.R. Multistage Gearbox Condition Monitoring Using Motor Current Signature Analysis and Kolmogorov-Smirnov Test. Sound Vib. 2006, 290, 337-368.

3. Yu, J.; He, Y. Planetary Gearbox Fault Diagnosis Based on Data-driven Valued Characteristic Multigranulation Model with Incomplete Diagnostic Information. Sound Vib. 2018, 429, 63-77. [CrossRef]

4. Aherwar, A.; Khalid, S. Vibration Analysis Techniques for Gearbox Diagnostic: A Review. Int. J. Adv. Eng. Technol. 2012, 3, 4-12.

5. Yang, D.; Liu, Y.; Li, S.; Li, X.; Ma, L. Gear Fault Diagnosis Based on Support Vector Machine Optimized by Artificial Bee Colony Algorithm. Mech. Mach. Theory 2015, 90, 219-229. [CrossRef]

6. Wang, D.-F.; Guo, Y.; Wu, X.; Na, J.; Litak, G. Planetary-Gearbox Fault Classification by Convolutional Neural Network and Recurrence Plot. Appl. Sci. 2020, 10, 932. [CrossRef]

7. Jin, X.; Cheng, F.; Peng, Y.; Qiao, W.; Qu, L. A Comparative Study on Vibration and Current-based Approaches for Drivetrain Gearbox Fault Diagnosis. In Proceedings of the IEEE Industry Application Society 52nd Annual Meeting IAS 2016, Portland, OR, USA, 2-6 October 2016; pp. 1-8.

8. Kar, C.; Mohanty, A.R. Vibration and Current Transient Monitoring for Gearbox Fault Detection Using Multiresolution Fourier Transform. J. Sound Vib. 2008, 311, 109-132. [CrossRef]

9. Mohanty, A.R.; Kar, C. Monitoring Gear Vibrations through Motor Current Signature Analysis and Wavelet Transform. Mech. Syst. Signal Process. 2006, 20, 158-187.

10. Zhang, J.; Dhupia, J.S.; Gajanayake, C.J. Stator Current Analysis from Electrical Machines Using Resonance Residual Technique to Detect Faults in Planetary Gearboxes. IEEE Trans. Ind. Electron. 2015, 62, 5709-5721. [CrossRef]

11. Cheng, F.Z.; Peng, Y.Y.; Qu, L.Y.; Qiao, W. Current-based Fault Detection and Identification for Wind Turbine Drivetrain Gearboxes. IEEE Trans. Ind. Appl. 2017, 53, 878-887. [CrossRef]

12. Kia, S.H.; Henao, H.; Capolino, G.A. Torsional Vibration Assessment Using Induction Machine Electromagnetic Torque Estimation. IEEE Trans. Ind. Electron. 2010, 57, 209-219. [CrossRef]

13. Da Silva, A.M.; Povinelli, R.J.; Demerdash, N.A. Induction Machine Broken Bar and Stator Short-circuit Fault Diagnostics Based on Three-phase Stator Current Envelopes. IEEE Trans. Ind. Electron. 2008, 55, 1310-1318. [CrossRef] 
14. Treetrong, J.; Sinha, J.K.; Gu, F.; Ball, A. Bispectrum of Stator Phase Current for Fault Detection of Induction Motor. ISA Trans. 2009, 48, 378-382. [CrossRef] [PubMed]

15. Inaki, B.L.; Hossein, D.A.; Liu, Z.C.; Alfredo, G.A.; Aitor, A.; Jay, L. Motor Current Signature Analysis for Gearbox Condition Monitoring Under Transient Speeds Using Wavelet Analysis and Dual-level Time Synchronous Averaging. Mech. Syst. Signal. Process. 2017, 94, 73-84.

16. Dineva, A.; Mosavi, A.; Gyimesi, M.; Vajda, I.; Nabipour, N.; Rabczuk, T. Fault Diagnosis of Rotating Electrical Machines Using Multi-Label Classification. Appl. Sci. 2019, 9, 5086. [CrossRef]

17. Kia, S.H.; Henao, H.; Capolino, G.A. Gear Tooth Surface Damage Fault Detection Using Induction Machine Stator Current Space Vector Analysis. IEEE Trans. Ind. Electron. 2014, 62, 1866-1878. [CrossRef]

18. Feng, Z.; Zuo, M.J. Fault Diagnosis of Planetary Gearboxes via Torsional Vibration Signal Analysis. Mech. Syst. Signal. Process. 2013, 36, 401-421. [CrossRef]

19. Wang, J.; Wang, J.; Du, W.; Zhang, J.; Wang, Z.; Wang, G.; Li, T. Application of a New Enhanced Deconvolution Method in Gearbox Fault Diagnosis. Appl. Sci. 2019, 9, 5313. [CrossRef]

20. Wang, W. Early Detection of Gear Tooth Cracking Using the Resonance Demodulation Technique. Mech. Syst. Signal Process. 2006, 20, 332-349. [CrossRef]

21. Feki, N.; Clerc, G.; Velex, P. Gear and Motor Fault Modeling and Detection Based on Motor Current Analysis. Electr. Power Syst. Res. 2013, 95, 28-37. [CrossRef]

22. Sanz, J.; Perera, R.; Huerta, C. Gear Dynamics Monitoring Using Discrete Wavelet Transformation and Multi-layer Perceptron Neural Networks. Appl. Soft Comput. 2012, 12, 2867-2878. [CrossRef]

23. Gu, F.; Shao, Y.; Hu, N.; Naid, A.; Ball, A.D. Electrical Motor Current Signal Analysis Using a Modified Bispectrum for Fault Diagnosis of Downstream Mechanical Equipment. Mech. Syst. Signal. Process. 2011, 25, 360-372.

24. Neil, A.; Jim, P. Induction Machine Condition Monitoring with Higher Order Spectra. IEEE Trans. Ind. Electron. 2000, 47, 1031-1041.

25. Ding, H.; Kahraman, A. Interactions between Nonlinear Spur Gear Dynamics and Surface Wear. J. Sound Vib. 2007, 307, 662-679. [CrossRef]

26. Yacamini, R.; Smith, K.S.; Ran, L. Monitoring Torsional Vibrations of Electromechanical Systems Using Stator Currents. J. Vib. Acoust. 1998, 120, 72-79. [CrossRef]

27. Feki, N.; Clerc, G.; Velex, P. An Integrated Electro-mechanical Model of Motorgear Units - Applications to Tooth Fault Detection by Electric Measurements. Mech. Syst. Signal Process. 2012, 29, 377-390. [CrossRef]

28. Chai, N.; Yang, M.; Ni, Q.N.; Xu, D.G. Gear Fault Diagnosis Based on Dual Parameter Optimized Resonance-based Sparse Signal Decomposition of Motor Current. IEEE Trans. Ind. Appl. 2018, 54, 3782-3792. [CrossRef]

29. Wang, L.; Liu, Z.W.; Cao, H.R.; Zhang, X. Subband Averaging Kurtogram with Dual-tree Complex Wavelet Packet Transform for Rotating Machinery Fault Diagnosis. Mech. Syst. Signal. Process. 2020, 142, 106755. [CrossRef]

30. Li, G.; Deng, C.; Wu, J.; Chen, Z.; Xu, X. Rolling Bearing Fault Diagnosis Based on Wavelet Packet Transform and Convolutional Neural Network. Appl. Sci. 2020, 10, 770. [CrossRef]

31. Li, F.; Pang, X.Y.; Yang, Z.J. Fault Diagnosis Method of Gear Broken and Wear Based on Motor Current Signature Analysis. Sci. Technol. Eng. 2018, 18, 48-52.

(C) 2020 by the authors. Licensee MDPI, Basel, Switzerland. This article is an open access article distributed under the terms and conditions of the Creative Commons Attribution (CC BY) license (http://creativecommons.org/licenses/by/4.0/). 